\title{
PENETRATION AND PERFORMANCE OF ISOCYANATE WOOD BINDERS ON SELECTED WOOD SPECIES
}

\author{
T. Michael Gruver ${ }^{a}$ and Nicole R. Brown ${ }^{\text {* }}$
}

The penetration and performance of polymeric diphenylmethane diisocyanate (pMDI) wood binder was investigated according to three factors: substrate species (aspen, yellow-poplar, or southern yellow pine); anatomical bonding plane (radial or tangential); and moisture content $(0 \%, 5 \%$, or $12 \%)$. Compression shear block tests and fluorescence microscopy were used to examine bond performance and resin penetration. Statistically, each of the aforementioned factors impacted results. As moisture content increased, observed bond strengths and wood failure increased. Bond formation did not occur when the substrates were equilibrated to $0 \%$ moisture content, except for the radial bonding surfaces of pine, which did adhere. At 5 and $12 \%$ moisture contents, tangential bonding surfaces out-performed radial bonding surfaces. In terms of resin penetration, moisture content was clearly the most important variable. Little penetration was observed at $0 \%$ moisture content, while extensive resin penetration was observed at elevated moisture contents. Pine was the only wood species to exhibit resin flow through radial cells, possibly explaining the enhanced resin penetration depths observed in pine samples.

Keywords: pMDI, Isocyanate, Adhesion, Fluorescence microscopy, Compression shear block tests, Resin penetration

Contact information: a: Hexion Specialty Chemicals Inc., 6210 Campground Road, Louisville, KY 40216

b: School of Forest Resources, Materials Research Institute, The Pennsylvania State University, 202

Forest Resources Building, University Park, PA 16802 USA; *Corresponding author: NRB10@PSU.EDU

\section{INTRODUCTION}

The widespread use of polymeric diphenylmethane diisocyanate (pMDI) binders in structural wood composites, coupled with the resin's unique cure chemistry, led to a number of fundamental research investigations regarding wood-pMDI interactions. Differential scanning calorimetry, dynamic mechanical analysis, dielectric analysis, nuclear magnetic resonance spectroscopy, and Fourier transform infrared spectroscopy (Weaver and Owen, 1995; Wendler and Frazier 1996a; Wendler and Frazier 1996b; Marcinko et al. 1998; Schmidt and Frazier 2000; Harper et al. 2001; Bao et al. 2003, He and Yan 2005; Das et al. 2006) all have been used to probe the wood-pMDI interphase, largely with the aim of understanding either the scale of intermolecular interactions between the resin and wood polymers or resin cure chemistry. Urethane formation between the resin and wood hydroxyl moieties was widely debated in the literature, but now is generally regarded as insignificant under common industrial manufacturing conditions. The mechanism underlying species-dependent performance of pMDI resin, however, remains unclear and is the motivation for this research. 
Johns et al. $(1982 ; 1985)$ conducted studies on the effects of pMDI in binding species-exclusive composite panels and found distinct performance differences. Much later, Malmberg (2002) and Das et al. (2006) observed species effects while testing pMDI-bonded wood double cantilever beams via mode I opening fracture testing. Das et al. also conducted solid state NMR and dynamic mechanical analyses to investigate these differences (2006). He and Yan (2005) studied pMDI cure on wood via DSC. To date, little has been done to explore the relationships between species-dependent performance and pMDI penetration for selected species, moisture contents, and bonding planes; these factors will be investigated in this paper.

Fluorescence microscopy was used to observe resin penetration at the micron scale. This technique is well established in the literature as a means of probing resin penetration within the wood-adhesive interphase (Brady and Kamke 1988; Johnson and Kamke 1992; Sernek et al. 1999; Conrad et al. 2004). Lap shear, internal bond, and fracture mechanics tests are all common means of evaluating the performance of thermosetting wood adhesives. However, each of these methods has inherent flaws for evaluating adhesion on solid wood substrates when sample orientation (bonding plane) is varied. Here, bond line performance was measured, following a widely used standard test method (ASTM D 905). Bigtooth aspen (Populus grandidenta), yellow-poplar (Liriodendron tulipifera), and southern yellow pine (Pinus spp.) wood species were selected due to widespread commercial usage and their prevalence in past research. Moisture contents (MCs) of $0 \%, 5 \%$, and 12\% were utilized, also due to commercial relevance and correlations with prior work.

\section{EXPERIMENTAL}

\section{Wood Sample Preparation}

The experimental design was a three by three by two factorial with three levels of species (aspen, poplar, pine), three levels of moisture content $(0 \%, 5 \%, 12 \%)$, and two levels of anatomical bonding plane (radial and tangential). Twenty compression shear blocks and five resin penetration samples (five measurements on each) were evaluated for each three-way factor combination, totaling 360 compression shear block tests and 450 resin penetration measurements. Compression shear block and fluorescence microscopy samples were taken from the same cured billet (Figure 1). Sapwood billets $(15.2 \mathrm{~cm} \mathrm{X}$ $1.27 \mathrm{~cm} \times 5.08 \mathrm{~cm}$ ) were prepared from kiln-dried boards equilibrated at $23^{\circ} \mathrm{C}$ and $40 \% \pm$ $2 \%$ relative humidity $(\mathrm{RH})$ such that either the radial or the tangential plane was exposed. Grain orientation was maintained such that "true" radial or tangential faces were obtained $\pm 15^{\circ}$; in rare cases variations in grain angle were observed up to $\pm 25^{\circ}$. Samples were equilibrated to moisture contents (MCs) of either $0 \%(0 \% \mathrm{RH}), 5 \%(25 \% \pm 2 \% \mathrm{RH})$, or $12 \%(67 \% \pm 2 \% \mathrm{RH})$ prior to bonding. Bayer Mondur ${ }^{\circledR} 541$ Light pMDI resin was applied with a dropper to freshly planed surfaces and then spread with a plastic applicator at an adhesive coverage of $80 \mathrm{~g} / \mathrm{m}^{2}$. Two adhesive-coated wood specimens (same species, and same planes exposed) were hot pressed at $175^{\circ} \mathrm{C}$ in a Carver Laboratory press for 25 minutes to form a cured billet (Figure 1). The hot press schedule was adapted from the work of Das et al. (2006), who prepared mode I opening fracture specimens; here the 
cure time was extended to account for thicker samples. Cure of each wood species*moisture content interaction was probed with dielectric analysis, using a Micromet Dielectric Analyzer and Idex sensors (data not shown). Each billet was machined into two compression shear blocks and one microscopy sample as shown in Figure 1.

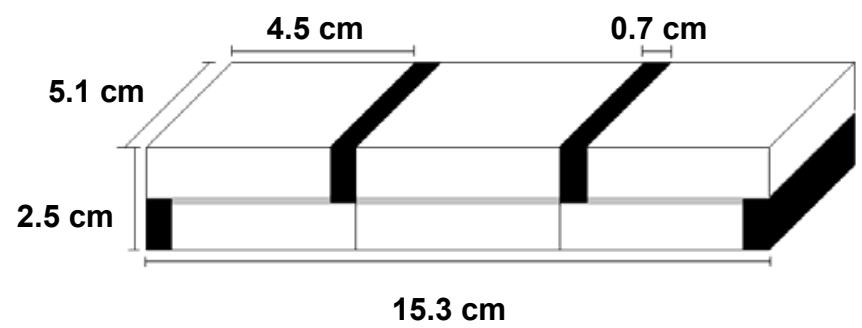

Fig. 1. Dimensions of a cured billet, where the bond line is the central horizontal gray line. Radial or tangential surfaces were bonded together to form the billet. Black portions were removed during machining, generating two compression shear blocks (ends) and one microscopy sample (middle).

\section{Compression Shear Block Testing}

Compression shear blocks were conditioned at $23^{\circ} \mathrm{C}$ and $40 \% \pm 2 \% \mathrm{RH}$ for one week prior to machining and testing. Samples were then loaded into a Tinius-Olsen testing machine fitted with an ASTM D 905 shear fixture. A continuous uniform loading rate of $0.51 \mathrm{~cm} / \mathrm{min}$ was applied until complete sample failure. Percent wood failure and shear stress at failure were recorded.

\section{Fluorescence Microscopy}

Bond line cross-sections were prepared with an American Optical microtome. Sample thickness varied between $50 \mu \mathrm{m}$ and $75 \mu \mathrm{m}$. Each section was placed in $0.5 \%$ ( $\mathrm{w} / \mathrm{w}$ in water) Toluidine-O-Blue (Harleco) solution for fifteen seconds, then sequentially rinsed in distilled water, then ethanol (Pharmco, 95\%). Samples were placed on glass slides with two to three drops of glycerol (J.T. Baker, 99\% pure), and a cover slip was placed on top. A total of five slides were prepared for each condition.

The fluorescence microscope was an Olympus BX-60 epi-fluorescent scope fitted with a Hamamatsu Orca-100 digital camera, a NIBA filter cube that allowed excitation wavelengths of $455 \mathrm{~nm}$ to $500 \mathrm{~nm}$, and a dicroic lens, which reflects light with wavelengths less than $500 \mathrm{~nm}$. Emission wavelengths of $505 \mathrm{~nm}$ to $560 \mathrm{~nm}$ were detected. Gain and exposure times were adjusted to minimize over-saturation. Measurements were taken with a $4 \mathrm{x}$ magnifying lens (40x magnification) and qualitative observations were made with either 10x or 20x magnifying lenses. Maximum resin penetration depth perpendicular to the bond line was measured (five times per sample at set interval spacing) with Image Pro v5.0 image analysis software.

\section{Statistical Methodology}

The statistical model for predicting the least squared means (Minitab, General Linear Model) was expressed as a function of the main effects (moisture content $(\alpha)$, 
wood species $(\beta)$, and bonding plane $(\gamma))$ plus the two- and three-way interactions of the main effects, as shown in Equation 1.

$$
\begin{array}{r}
M_{i j k}=\mu+\alpha_{i}+\beta_{j}+\gamma_{k}+(\alpha \beta)_{i j}+(\alpha \gamma)_{i k}+(\beta \gamma)_{j k}+(\alpha \beta \gamma)_{i j k} \\
\text { Where: } i=1,2,3 \quad j=1,2,3 \quad k=1,2
\end{array}
$$

Analyses of variance (ANOVA) with Tukey multiple comparison tests were used to evaluate the data, where the criterion for significance was $\alpha=0.10$. Data are illustrated via interaction plots where sample means are represented by a symbol and error bars represent the $90 \%$ confidence intervals about the means.

\section{RESULTS AND DISCUSSION}

\section{Performance of Bonded Specimens}

Statistical analysis of the compression shear block data revealed that all two- and three-way interactions of the factors were significant at $\alpha=0.10$. Two-way interaction plots demonstrate the effects of the factors on bond shear strength and wood failure.

Out of the 120 billets bonded at $0 \% \mathrm{MC}, 100(\sim 83 \%)$ failed to bond during the press cycle. Dielectric studies were conducted to monitor the extent of cure during hot pressing, however, at $0 \% \mathrm{MC}$ no conclusive evidence for cure emerged due to extreme variability among the data. This raises the possibility that the samples were only partially cured - one potential explanation for the poor bonding. Alternatively, the dry conditions could have caused the isocyanate resin to act as a wood modification agent rather than a highly networked resin. Previous studies offer some support for this theory, as cure under dry conditions has been speculated to be due to urethane formation at accessible wood hydroxyl groups (Weaver and Owen 1995, He and Yan 2005). Under these dry conditions, the resin is not extensively networked, causing poor stress transfer and poor bonding. It should be noted that the 20 samples that did bond were all southern yellow pine samples with radial surfaces adhered. Of these 20 samples, five failed when the compression shear block samples were machined from the billet; the remaining 15 samples had $0 \%$ wood failure and failed at low average shear stress $\left(8.34 \times 10^{5} \mathrm{~N} / \mathrm{m}^{2}\right)$. The discovery that radial pine samples adhered at $0 \%$ moisture was unexpected. This finding may suggest that ray tissues have a unique interaction with pMDI. The surface chemistry in the rays may be different, or the morphology of the surface could be different, although these are both speculative comments. Little work has been conducted regarding the surface roughness or surface characterization of ray tissues.

Figures 2 and 3 reveal the effects of bonding the selected species at either $5 \%$ or $12 \%$ moisture content. Under these conditions, all samples bonded and corresponding dielectric data revealed complete cure. A networked topology based on polyurea dominates when moisture is present, thus providing resistance to applied loads (Weaver and Owen 1995, Zhou and Frazier 2001). Generally, wood failure data (Figure 3) paralleled the responses seen in the shear stress at failure data (Figure 2), with the exception that the variability was higher in the wood failure data. Wood failure is by 
nature variable; nevertheless it remains an important component of the ASTM D 905 protocol. Data obtained here show surprisingly good correlations between wood failure and observed shear stress at failure; in Figure 7 the variability becomes more obvious. In terms of shear stress (Figure 2), results indicated that at 5\% moisture content, southern pine and aspen samples behaved similarly, both performing better than yellow-poplar. When moisture content increased from 5 to $12 \%$, ultimate shear stresses increased for each wood species, as did wood failure (Figure 3). Yellow-poplar showed the most pronounced sensitivity to moisture content, both in terms of wood failure and shear stress at failure.

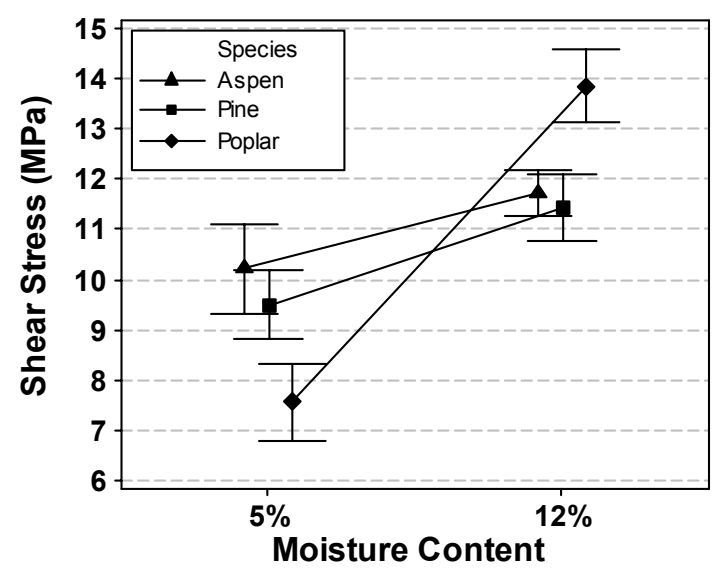

Fig. 2. Interaction plot of moisture content versus mean shear stress (A) as a function of wood species (all orientations pooled).

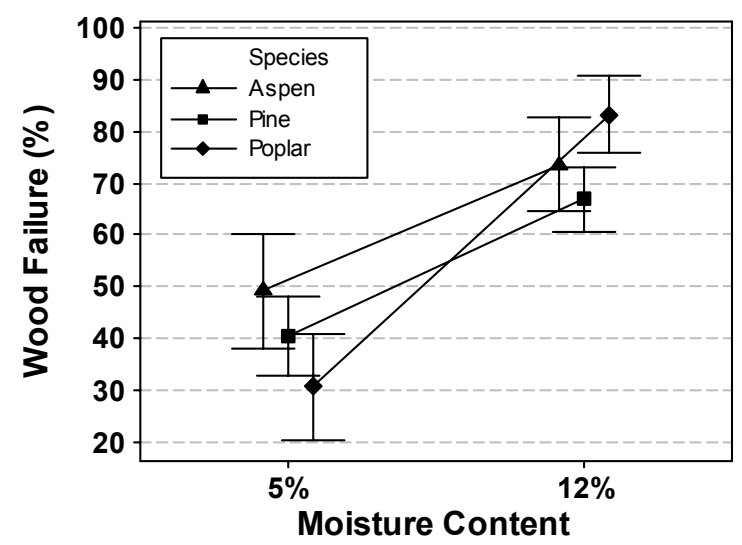

Fig. 3. Interaction plot of wood failure versus wood moisture content as a function of species (anatomical faces pooled).

\section{Effects of Species and Anatomical Bonding Plane}

At 5\% moisture content, the bonding plane did not impact shear stress at failure, but at $12 \% \mathrm{MC}$, the tangentially bonded samples performed better than the radially bonded samples, as expected. Differences due to the anatomical planes were not evident 
in the wood failure data; however, the trend of better performance at higher moisture contents is again supported (Figure 5).

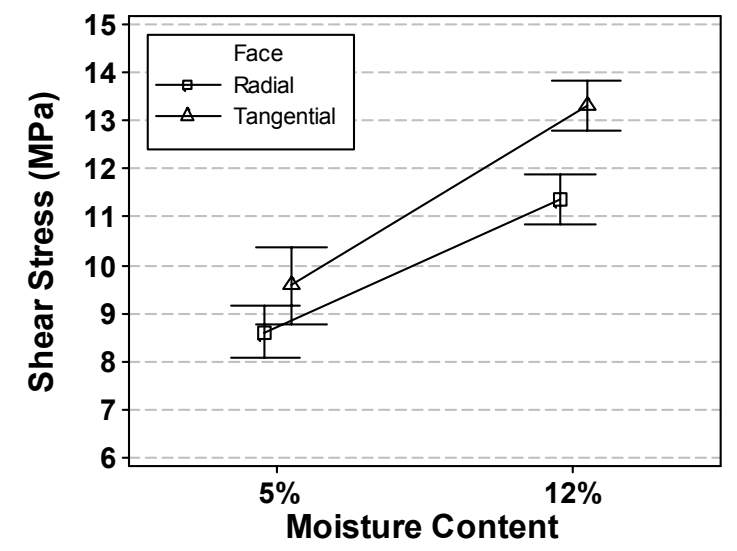

Fig. 4. Interaction plot of moisture content versus mean shear stress as a function of anatomical bonding surface (all species pooled).

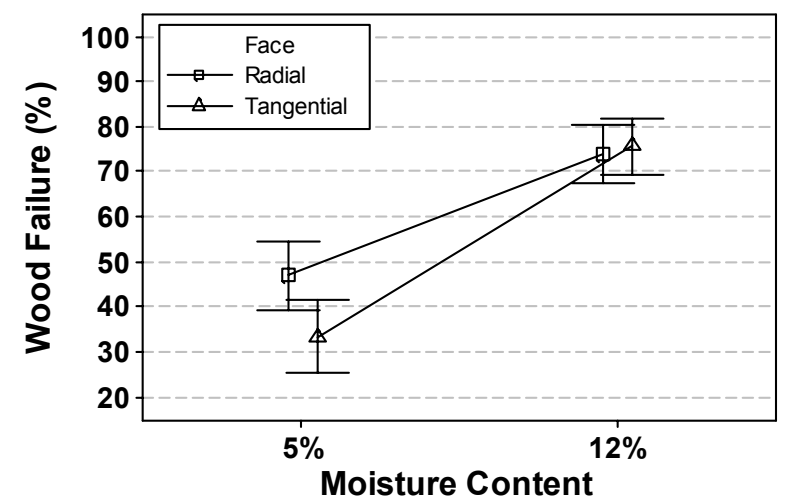

Fig.5. Interaction plot of wood failure versus wood moisture content as a function of face (species pooled).

Interactions between species and anatomical faces were only statistically significant for aspen samples (Figures 6), which had enhanced performance when tangential faces were bonded. The effect of substrate orientation and exposed resin penetration paths will be discussed further in the fluorescence microscopy section of this article. When tangential faces were bonded, there were no differences among the species; all radially bonded faces were also statistically identical, except the pine samples at $0 \%$ moisture content, which were previously described. Wood failure data (Figure 7) revealed no significant differences according to anatomical planes or species.

Very few research articles have investigated the strength of the pMDI-wood bond line in solid wood specimens. The fracture mechanics results obtained by Das et al. (2006) included southern yellow pine and yellow-poplar specimens bonded at $10 \% \mathrm{MC}$. Malmberg (2002) speculated that the higher initiation and arrest energies observed for pine were due in part to the higher surface free energy measured for pine. The $10 \% \mathrm{MC}$ 
level used by Malmberg (2002) is not replicated here. However, our results at 5\% MC are similar to their findings (pine samples out-performed poplar in observed shear stress at failure). Our data indicates that this trend reverses at $12 \% \mathrm{MC}$ (poplar out-performs pine), suggesting that the high surface free energy of pine is not the only factor influencing adhesion. Other important factors to consider regarding species-specific adhesion (also noted by Das et al. 2006) include: slight differences in cure chemistry, differences in interphase morphology, and differences in heat and mass transfer during hot pressing due to different wood anatomical features.

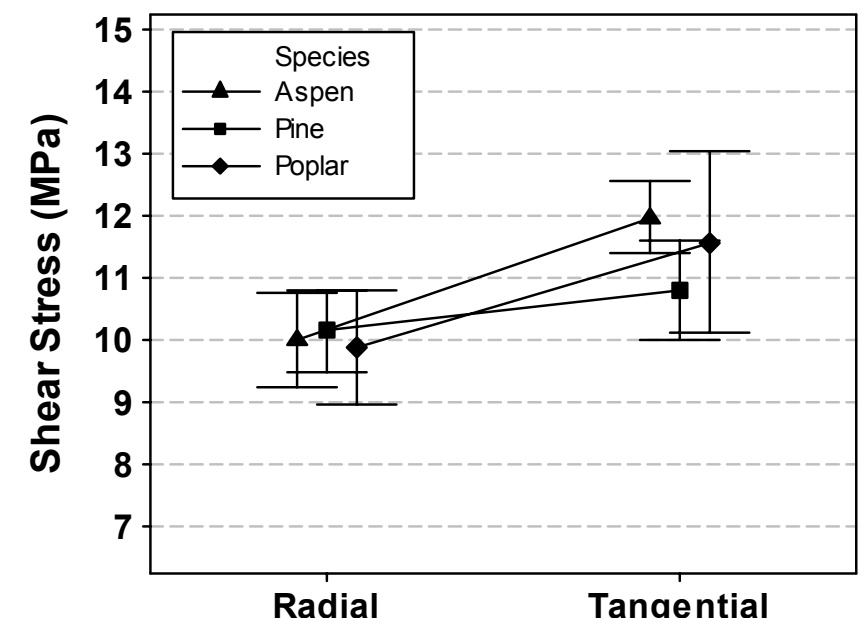

Fig. 6. Interaction plot of anatomical bonding plane versus mean shear stress as a function of wood species (all moisture contents pooled).

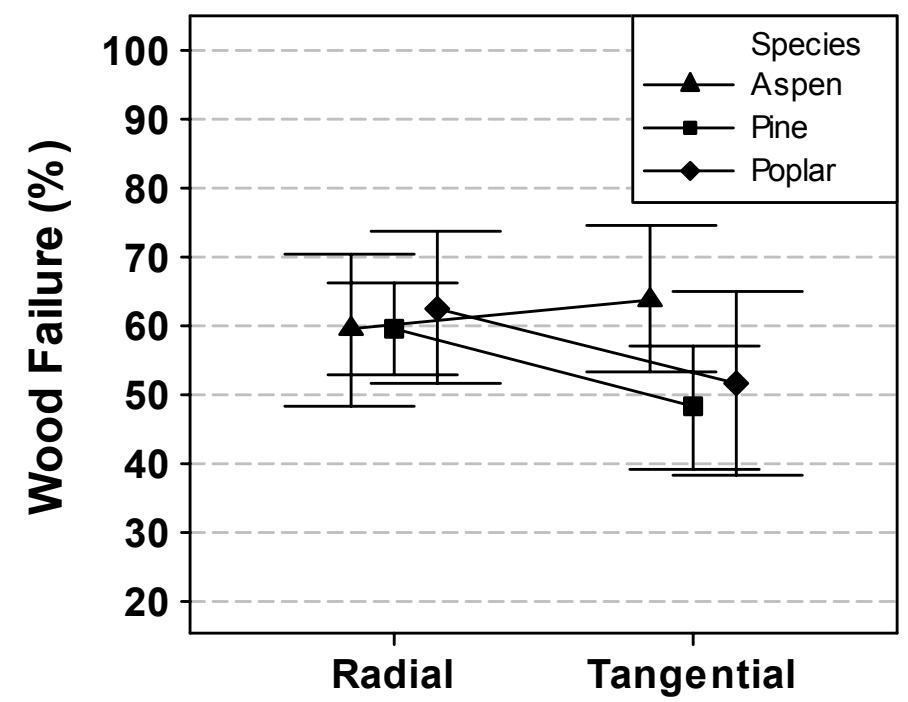

Fig. 7. Interaction plot of anatomical bonding plane versus mean wood failure as a function of wood species (all moisture contents pooled). 


\section{Resin Penetration}

Factors Influencing Resin Penetration

One of the principle objectives here was to examine the effects of wood anatomy on resin penetration. Of the commercially important species used in OSB production, one softwood and two hardwood species were selected for study. Differences in hardwood and softwood structure are well documented, but the flow of adhesives and resins through specific anatomical tissues is not. Softwoods have a fairly homogeneous cell structure, constituted of more than $90 \%$ longitudinal tracheids, whereas hardwood structure is notably more heterogeneous. While vessels are the principle vehicle for bulk flow in hardwoods, softwood fluid flow occurs primarily through tracheid lumens, ray lumens, and the interconnecting pits (Siau, 1995). Radial permeability exceeds tangential permeability in softwoods, owing to the important contribution of rays (Banks, 1970). In hardwoods, this discrepancy is not as apparent. For unknown reasons, conduction through hardwood ray tissues is not nearly as important, despite the greater abundance of rays (Siau, 1995). Differences are also clear when comparing penetration in earlywood and latewood tissues. In softwoods, latewood tissues are generally more permeable than earlywood. This is presumed to be due to the more rigid pit membranes (tori) of latewood, which are less likely to be aspirated (Siau, 1995). Diffuse porous hardwood species show little difference in penetration between latewood and earlywood, as the pits in hardwoods lack tori, and thus cannot be aspirated (Siau, 1995).

The polarity of the resin is also expected to affect penetration. Independent research by Walters and Cote (1960), and Murmanis and Chudnoff (1979) suggested that nonpolar liquids travel via bulk flow through cell lumens and pitting. Polar compounds penetrate via both bulk flow and by diffusion through the wood cell wall. This raises an interesting question regarding the mechanism of pMDI penetration. While unreacted pMDI is non-polar, its hydrophilicity and polarity increase as it reacts with water present in wood. In addition to affecting the mechanism of pMDI flow, wood moisture content also impacts the ultimate penetration depth of pMDI. It is well known that the permeability of wood tissues is proportional to moisture content. Intercellular pitting becomes impermeable under dry conditions, suggesting that polar liquids must be present to facilitate penetration (Stamm 1953; Stone and Green 1959; Wardrop and Davies 1961; Murmanis and Chudnoff 1979). While increasing moisture contents favor tissue permeability, they also lead to pMDI cure, which increases resin viscosity and limits resin penetration. Thus, the pathway and extent of pMDI penetration in wood is difficult to predict.

Here, limited resin penetration was observed under dry conditions (Figure 8), especially for the two hardwood species, indicating that the effect of increased viscosity is not as important as the resin's accessibility to wood's ultrastructure. Note that above $0 \%$ moisture content, resin penetration remains constant for a given species. Pine has maximum penetration, and aspen minimum penetration. We observed that pine is the only species to show evidence of adhesive penetration through ray tissues, confirming Siau's observation that flow through rays is more important in softwoods than hardwoods (1995). Figure 9 further supports this observation, in that resin penetration is far greater when tangential surfaces are bonded. In this orientation, resin can flow through the open ends of rays and penetrate wood more deeply. In the two hardwoods, flow through the 
exposed ends of rays did not contribute to enhanced resin penetration. In aspen, there is a notable decrease in penetration in this orientation. The reason for this decrease is not clear.

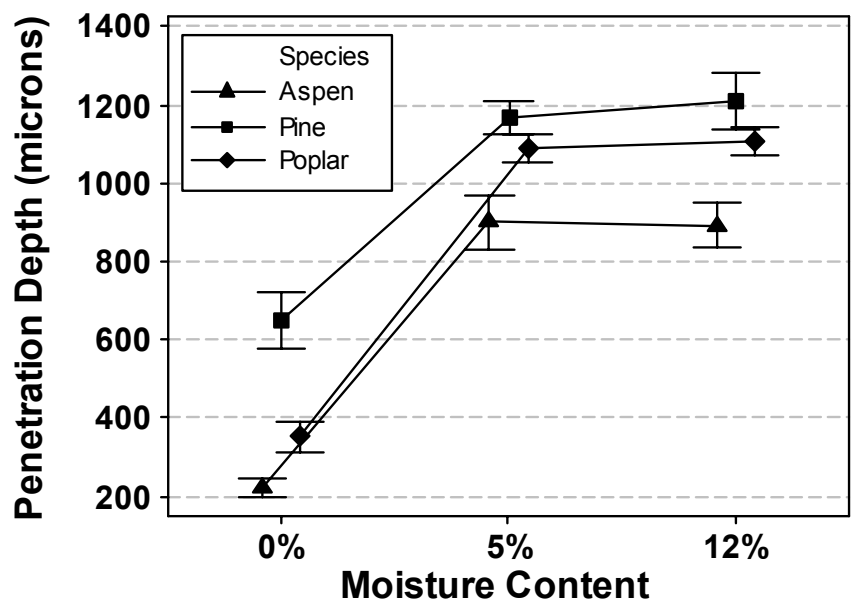

Fig. 8. An interaction plot of moisture content versus mean resin penetration depth as a function of wood species (all orientations pooled).

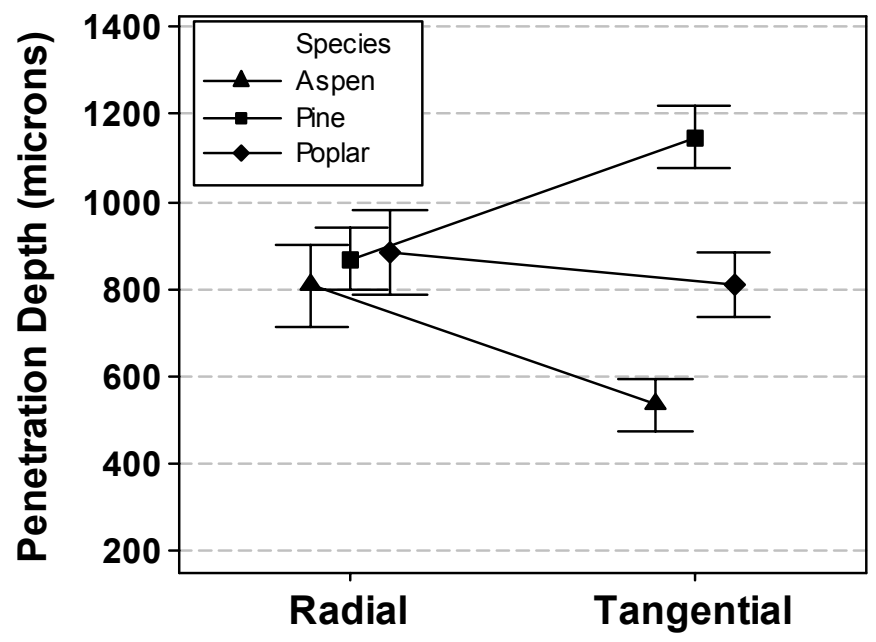

Fig. 9. An interaction plot of anatomical bonding plane versus mean resin penetration depth as a function of wood species (all moisture contents pooled).

\section{Qualitative Features of Resin Penetration}

Representative cross-sectional micrographs of resin penetration into radial and tangential bonding surfaces for aspen, poplar, and pine at $0 \% \mathrm{MC}$ are shown in Figure 10, while micrographs at higher moisture contents are shown in Figure 11. There were no significant differences for resin penetration between $5 \%$ and $12 \% \mathrm{MC}$, therefore these micrographs are grouped in Figure 11. Fluorescing regions indicate the presence of pMDI resin. 

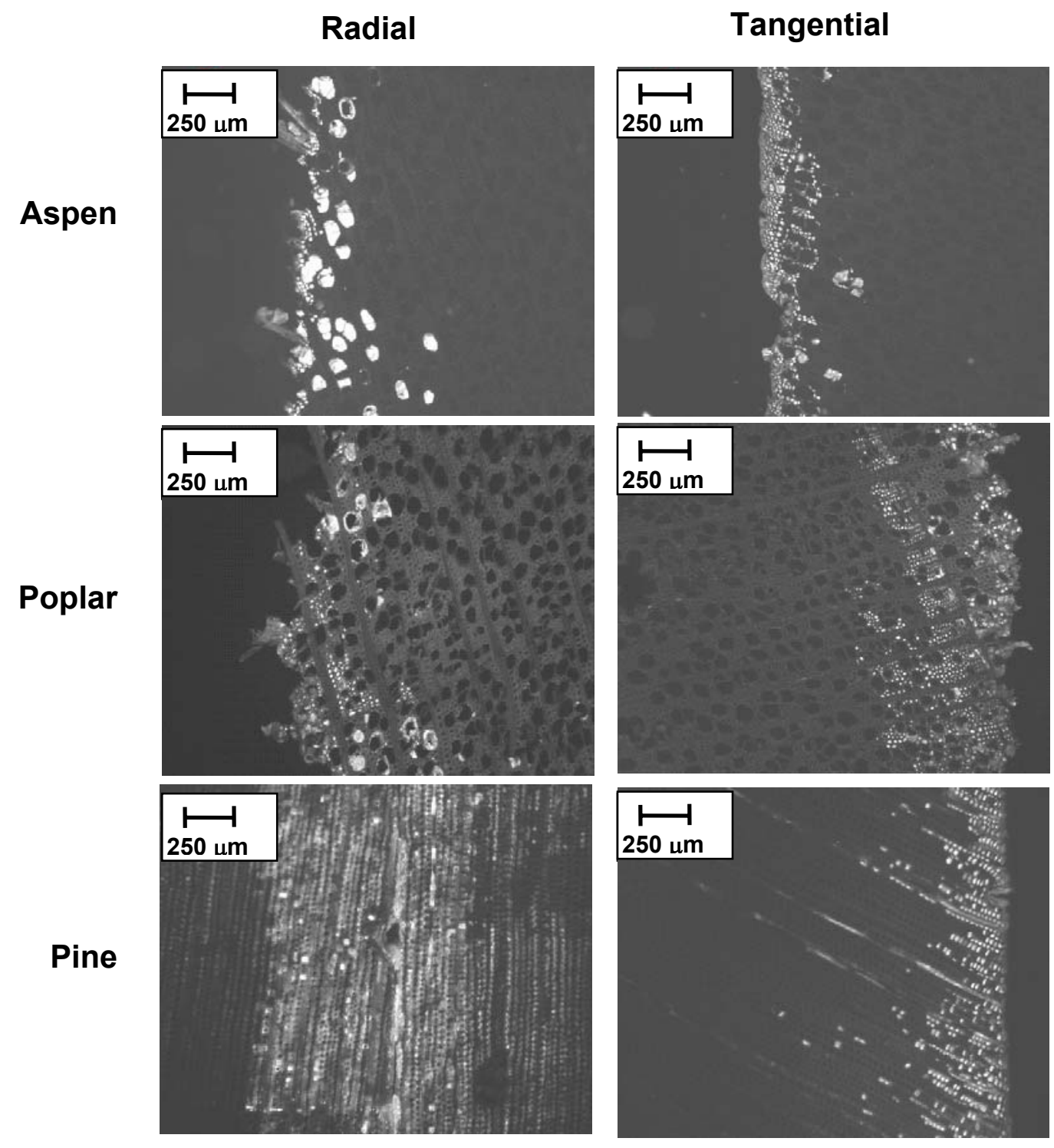

Fig. 10. Resin penetration into radial and tangential surfaces for aspen, poplar, and pine at $0 \%$ MC.

The figures reveal less resin penetration at $0 \% \mathrm{MC}$ than at elevated MCs (confirming the results of Figure 8), and indicate the different distributions of resin according to the species and bonding plane exposed. Note that a high proportion of vessel elements (hardwoods) and lumens (all species) are completely filled with resin at $0 \%$ moisture content (Figure 10), but not at higher moisture contents (Figure 11). This lends support to the observation that resin penetration is highly dependent upon the accessibility of the resin to wood tissues. In cases where the wood is completely dry, the resin cannot penetrate far, thus it is limited to cell lumens. Note that pine ray tissues contain pMDI under all moisture conditions, but hardwoods did not show evidence of pMDI in ray tissues. This was referred to previously as support for increased penetration 
when tangential surfaces of pine are bonded (Figure 9). Note that in hardwoods under dry conditions (Figure 10), the resin almost always appears in the cell lumens of fiber tracheids when applied to the tangential faces; further, it seems to prefer latewood lumens. This latewood preference was even more distinct in pine samples (Figure 11, lower right), a finding in support of Siau's claim that latewood tissues of softwoods are more permeable.

When moisture was present (Figure 11), the resin lightly coated the cell lumens and/or vessel walls instead of completely filling them. Also, the resin was mostly found in the vessel cells of the hardwood species, very rarely being evident in the longitudinal fibers. In pine, resin clearly preferred latewood tissues. Under these circumstances, the influence of steam generation on resin penetration, as mentioned by Brady and Kamke (1988) and Sernek et al. (1999), cannot be neglected. However, it is interesting to note that resin penetration differences between 5\% MC to $12 \% \mathrm{MC}$ are not evident, suggesting that either the effect due to steam generation at these MCs may be limited, or that some minimal level of steam is all that is required to promote penetration. Studying resin penetration at higher moisture content conditions would contribute to a greater understanding of the role of steam in the system. No studies to date have accounted for the carbon dioxide $\left(\mathrm{CO}_{2}\right)$ formed when isocyanate and water react, and this could similarly influence resin penetration.

Previous research quantitatively observing pMDI resin penetration is sparse. Buckley et al. (2002) studied pMDI penetration in aspen with chemical-state x-ray microscopy and found that resin travels via bulk flow through the cell lumens and pits. Zheng et al. (2004) determined pMDI penetration is greater in yellow-poplar than in southern yellow pine. These results conflict with results in this study. Zheng et al. (2004) also determined, via fluorescence microscopy, that pMDI had similar or less penetration than neat phenol formaldehyde (PF) resin, a surprising finding given the lower viscosity and lower surface free energy of pMDI. They attributed the limited extent of pMDI penetration to diffusion into the cell wall, which cannot be resolved via fluorescence microscopy. Evidence for cell wall penetration of pMDI was first noted by Marcinko et al. (1999) and later by Schmidt and Frazier (2000). The techniques used here cannot compare the extent of pMDI penetration into the cell wall; however, this issue will be explored by future dynamic mechanical analyses.

\section{Correlations between Performance and Resin Distribution}

Both shear stress at failure and resin penetration improved when the moisture content of the wood increased from $0 \%$ to either $5 \%$ or $12 \%$. Overall, the correlation between shear stress at failure and maximum resin penetration depth was found to be quite weak $\left(\mathrm{r}^{2}=0.59\right)$. This is not surprising, as the influence of resin penetration on performance is difficult to resolve.

Further, correlations with performance may be limited by the inherent variability of the compression shear block test method. In cases where the substrate fails prior to the adhesive (true for virtually all cases for 5 and $12 \% \mathrm{MC}$ ), the true measure of "adhesion" is not obtained. This is a well-known limitation of the compression shear block test, yet it remains the industry standard method for probing wood-adhesive performance. 
This study did not investigate the surface chemistry of the selected species. Resin wetting and contact angle studies could contribute to the overall understanding of species effects, resin distribution, and performance for pMDI resins.

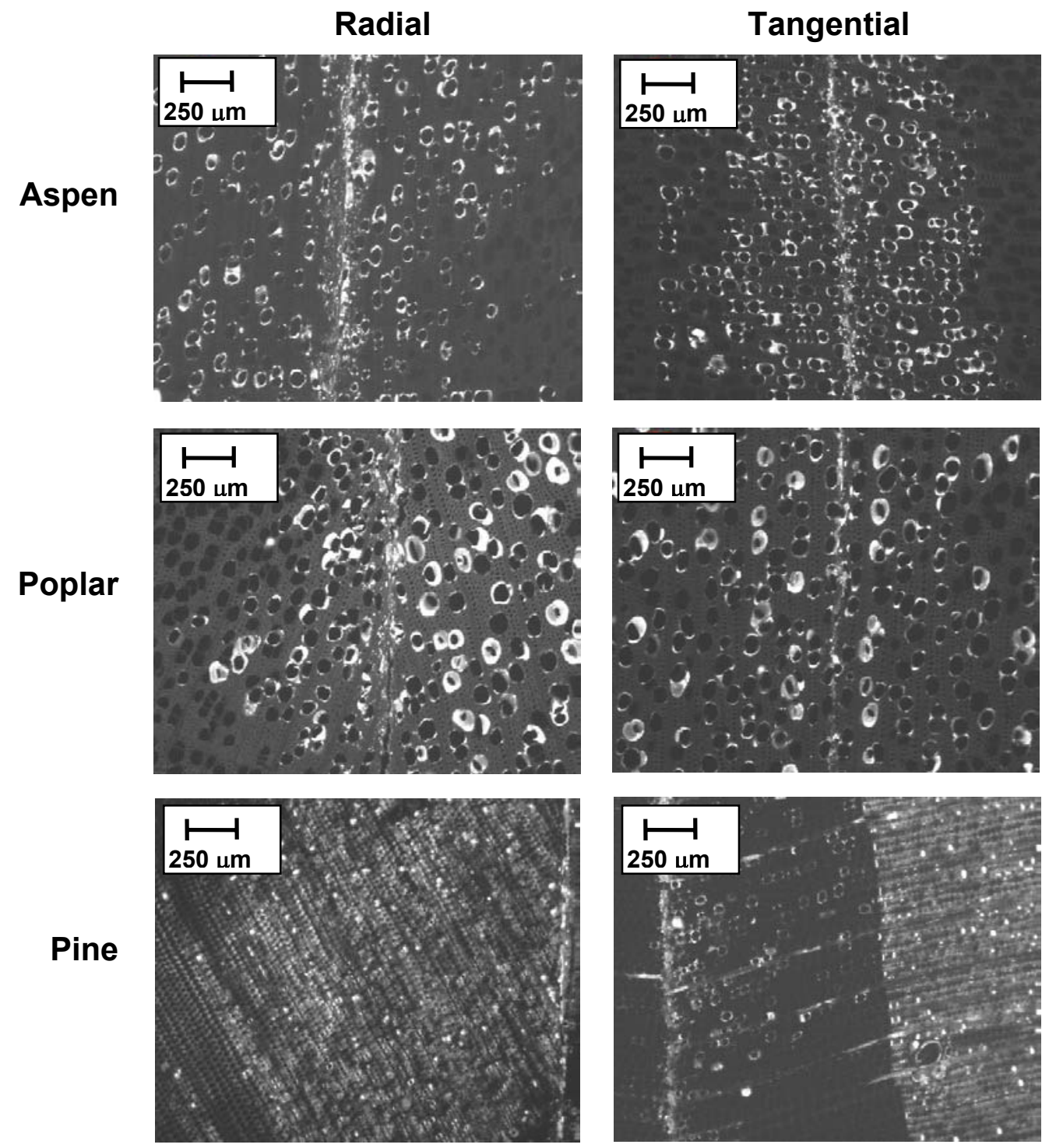

Fig. 11. Resin penetration into radial and tangential surfaces for aspen, poplar, and pine at $5 \%$ $\mathrm{MC}$ and $12 \% \mathrm{MC}$.

\section{CONCLUSIONS}

1. All factors investigated (wood species, moisture content, and bonding surface), and the interactions of these factors, had statistically significant effects on shear stress at failure and resin penetration. 
2. Bond formation did not occur at $0 \% \mathrm{MC}$, except for the radial bonding surface of pine.

3. Performance increased with MC for all wood species; poplar displayed the greatest sensitivity to moisture.

4. Moisture content affected resin penetration in all wood species; little resin penetration was observed at $0 \% \mathrm{MC}$ and extensive resin penetration was observed at elevated moisture contents. The differences at elevated moisture are attributed to intercellular structures and their ability to inhibit fluid flow in dry wood.

5. Resin filled lumens and vessels at $0 \% \mathrm{MC}$ but only lightly coated them at elevated moisture levels.

6. Pine was the only wood species to exhibit resin flow through radial cells, possibly enhancing resin penetration.

7. Anatomical bonding surfaces affected resin penetration for pine (as mentioned previously) and for aspen.

8. Resin preferred latewood regions of wood, particularly in pine.

9. Bond performance was greater for tangential bonding surfaces than radial bonding surfaces.

10. Resin penetration and bond line performance show a weak correlation.

\section{ACKNOWLEDGMENTS}

The authors are grateful for the support of Bayer MaterialScience who donated the pMDI resin, John Janowiak, who provided the use of his testing equipment, and the Penn State Flow Cytometry personnel, who contributed their expertise in fluorescence microscopy.

\section{REFERENCES CITED}

American Society for Testing and Materials (ASTM) (2003). Method D 905-03, 27-30. Banks, W.B. (1970). "Some factors influencing the permeability of Scots pine and Norway spruce," J. Inst. Wood Sci. 5(1), 10-17.

Bao, S., Daunch, W. A., Sun, Y., Rinaldi, P. L., Marcinko, J. J., and Phanopoulos, C. (2003). "Solid state two-dimensional NMR studies of polymeric diphenylmethane diisocyanate (pMDI) reaction in wood," Forest Prod. J. 53(6), 63-71.

Brady, D. E., and Kamke, F. A. (1988). "Effects of hot-pressing parameters on resin penetration," Forest Prod. J. 38(12), 63-68.

Buckley, C. J., Phanopoulos, C., Khaleque, N., Engelen, A., Holwill, M. E. J., and Michette, A. G. (2002). "Examination of the penetration of polymeric methylene diphenyl-di-isocyanate (pMDI) into wood structure using chemical state X-ray microscopy," Holzforschung 56(2), 215-222.

Conrad, M. P. C., Smith, G. D., and Fernlund, G. (2004). "Fracture of wood composites and wood-adhesive joints: A comparative review," Wood Fiber Sci. 36(1), 26-39. 
Das, S., Malmberg, M. J., and Frazier, C. E. (2006). "Cure chemistry of wood/polymeric isocyanate (PMDI) bonds: Effect of wood species. Int. J. Adhesion Adhesives. In press.

Harper, D. P., Wolcott, M. P., and Rials, T. G. (2001). "Evaluation of the cure kinetics of the wood/pMDI bondline," Int. J. Adhesion Adhesives. 21(2), 137-144.

He, G., and Yan, N. (2005). "Effect of moisture content on curing kinetics of pMDI resin and wood mixtures," Int. J. Adhesion Adhesives. 25(5), 450-455.

Johnson, S. E., Kamke, F. A. (1992). "Quantitative analysis of gross adhesive penetration in wood using fluorescence microscopy." J. Adhesion 40(1), 47-61.

Johns, W. E., Maloney, T. M., Saunders, J. B, Huffaker, E. M., and Lentz, M. T. (1982). "The effect of species and moisture content on the bonding efficiency of polymeric MDI isocyanate," Proceedings of the $16^{\text {th }}$ International Particleboard Symposium, Washington State University, Pullman, Washington, 71-98.

Johns, W. E., Rammon, R., and Youngquist, J. (1985). "Chemical effects of mixed hardwood furnish on panel properties," Proceedings of the $19^{\text {th }}$ International Particleboard and Composite Materials Symposium, Washington State University, Pullman, Washington, 363-377.

Malmberg, M. J. (2002). "Wood dependence of pMDI/wood adhesion," Thesis, Virginia Polytechnic Institute and State University. Blacksburg, Virginia.

Marcinko, J. J., Rinaldi, P. J., and Bao, S. (1999). "Exploring the physicochemical nature of pMDI/wood structural composite adhesion," Forest Prod. J. 49(5), 75-78.

Marcinko, J. J., Devathala, S., Rinaldi, P. J., and Bao, S. (1998). "Investigating molecular and bulk dynamics of pMDI/wood and UF/wood composites," Forest Prod. J. 48(6), 81-84.

Murmanis, L., and Chudnoff, M. (1979). "Lateral flow in beech and birch as revealed by the electron microscope," Wood Sci. Technol. 13, 79-87.

Schmidt, R. G., and Frazier, C. E. (2000). "Cross-polarization studies of interphase morphology in the wood-pMDI adhesive bondline," Compos. Interfaces 7(2), 93-102.

Sernek, M., Resnik, J., and Kamke, F. A. (1999). "Penetration of liquid ureaformaldehyde adhesive into beech wood," Wood Fiber Sci. 31(1), 41-48.

Siau, J. F. (1995). "Wood: Influence of moisture on physical properties," Department of Wood Science and Forest Products, Virginia Polytechnic Institute and State University, Blacksburg, Virginia, 227 pgs.

Stamm, A. J. (1953). "Diffusion and penetration mechanism of liquids into wood," Pulp Paper Mag. Can. 54(2), 54-63.

Stone, J. E., and Green, H. V. (1959). "Penetration and diffusion into hardwoods," TAPPI 42(8), 700-709.

Walters, C. S., and Cote, W. A. (1960). "The distribution of pentachlorophenol in the microstructure of basswood," Holzforschung 14, 183-189.

Wardrop, A. B., and Davies, G. W. (1961). "Morphological factors relating to the penetration of liquids into wood," Holzforschung 15, 129-141.

Weaver, F. W. and Owen, N. L. (1995). "Isocyanate-wood adhesive bond," Appl. Spectroscopy, 49(2), 171-176. 
Wendler, S. L., and Frazier, C. E. (1996). "Effect of moisture content on the isocyanate/wood adhesive bondline by ${ }^{15} \mathrm{~N}$ CP/MAS NMR," J. Appl. Polym. Sci. 61(5), 775-782.

Wendler, S. L., and Frazier, C. E. (1996). "The effects of cure temperature and time on the isocyanate-wood adhesive bondline by ${ }^{15} \mathrm{~N}$ CP/MAS NMR," Int. J. Adhesion Adhesives. 16(3), 179-186.

Zheng, J., Fox, S. C., and Frazier, C. E. (2004). "Rheological, wood penetration, and fracture performance studies of PF/pMDI hybrid resins," Forest Prod. J. 54(10), 7481.

Zhou, X., and Frazier, C. E. (2001). "Double labeled isocyanate resins for the solid-state NMR detection of urethane linkages to wood," Int. J. Adhesion Adhesives. 21(3), 259-264.

Article submitted: July 26, 2006; First round of reviewing completed Sept. 22, 2006;

Revised version accepted: November 4, 2006; Published November 5, 2006. 